\title{
A Systematic Review of School-Based Alcohol and other Drug Prevention Programs
}

\author{
Roberta Agabio ${ }^{1, *}$, Giuseppina Trincas ${ }^{2}$, Francesca Floris ${ }^{2}$, Gioia Mura ${ }^{2}$, Federica Sancassiani $^{2}$ \\ and Matthias C. Angermeyer ${ }^{2,3}$
}

\author{
${ }^{I}$ Department of Biomedical Sciences, Section of Neuroscience and Clinical Pharmacology, University of Cagliari, \\ Cagliari, Italy; ${ }^{2}$ Department of Public Health and Clinical and Molecular Medicine and Unit of Psychosomatics and \\ Clinical Psychiatry, University Hospital, University of Cagliari, Cagliari, Italy; ${ }^{3}$ Center for Public Mental Health, \\ Gosim, Austria
}

\begin{abstract}
Background: Alcohol use in adolescents constitutes a major public health concern. Europe is the heaviest drinking region of the world. Several school-based alcohol prevention programs have been developed but it is not clear whether they are really effective. The present study was aimed at identifying the typology with the best evidence of effectiveness in European studies. Methods: A systematic search of meta-analyses and/or randomized controlled trials (RCTs) on interventions school-based prevention programs aimed at preventing alcohol consumption or changing the attitudes to consume alcohol. Results: A meta-analysis published in 2011 and 12 RCTs more recently published were identified. The meta-analysis evaluated 53 RCTs but only $11.3 \%$ of them were conducted in Europe. Globally, 23 RCTs (43.4\%) showed some evidence of effectiveness, and $30 \mathrm{RCTs}(56.6 \%)$ did not find significant difference between the groups. According to the conclusions of the meta-analysis, the Unplugged program should be considered as a practice option in Europe. Among the other 12 RCTs, $42 \%$ were conducted in Europe. Globally, 7 studies (58.3\%) achieved positive results, and 5 studies $(41.7 \%)$ did not find significant differences or produced a mixed pattern of results. Three of the 5 European trials $(60 \%)$ used the Unplugged program with positive results. Conclusion: Even if further studies should be conducted to confirm these results, Unplugged appears to be the prevention project with the best evidence of effectiveness in European studies.
\end{abstract}

Keywords: Drinking, prevention, school.

\section{INTRODUCTION}

Alcohol consumption is one of the major risk factors for morbidity and mortality worldwide [1]. It increases the risks to develop many disease categories such as alcohol dependence, cancer, cardiovascular disease, liver cirrhosis, and injuries [1]. The risks are directly related with the average volume of alcohol consumption, and heavy drinking is related with intentional and unintentional injuries, homicide, suicide, violence, criminal activity, poor health, risky sexual behaviour, and pregnancy [1]. It has been estimated that alcohol is responsible of $3.8 \%$ of all global deaths, $6.3 \%$ for men and $1.1 \%$ for women [1]. The difference between the sexes is due to the difference in drinking as, in all regions worldwide, men consume more alcohol than women [1]. However, evidence of gender convergence has emerged [2].

Alcohol use in adolescents constitutes a major public health concern. Despite their particular vulnerability to the effects of alcohol, drinking to intoxication is reported to be common in teenagers [3-6]. Namely, a particular risky drinking pattern called binge drinking - defined as consuming five

\footnotetext{
*Address correspondence to this author at the Department of Biomedical Sciences, Section of Neuroscience and Clinical Pharmacology, University of Cagliari, Cittadella Universitaria, S.S. 554, km. 4.500, I-09042 Monserrato (CA), Italy; Tel: +39 070 6754325; Fax: +39 070 6754320;

E-mail: agabio@unica.it
}

drinks or more on the same occasion - is widely diffuse. Exposure of the developing brain to alcohol disrupts cortical development and alters higher executive functions in a manner that promotes continued impulsive behaviour, with heavy alcohol consumption increasing the likelihood of alcohol dependence [4]. Detectable structural abnormalities have been described in the brain of adolescents that assumed elevated amounts of alcohol due to an interaction between adolescent brain development and alcohol exposure [7]. Moreover, subjects who start drinking before the age of 14 are four times more likely to become alcohol dependent at some time in their life as compared to those who first consume alcohol at the age of 20 or older [8]. Elevated alcohol consumption alone has been estimated to cause more than $30 \%$ of all deaths in 15-29 year old men in the developed world [6]. More young people die from the acute effects of alcohol rather than the long-term ones.

Europe is the heaviest drinking region of the world, drinking 11 litres of pure alcohol per adult, each year [1]. In many countries, alcohol use by people under the age of 18 is illegal. However, the use of alcohol in adolescents is extremely widespread. For instance, a large study recently carried out, the European School Survey Project on Alcohol and Other Drugs (ESPAD), through the administration of a questionnaire to more than 100,000 students from 35 European countries, found that, in Europe, approximately $90 \%$ of 
15-16 year-old students have drunk alcohol at least once in their life, with $50 \%$ of these having become intoxicated at least once [9]. Drinking among adolescents is a very difficult behavior to intervene upon, but considering these data, the need for effective prevention is clear [10].

Traditional classification of prevention approaches includes primary, secondary, and tertiary strategies. Primary prevention is aimed at reducing risks and preventing new cases, secondary prevention at limiting harm in the early stages of a disorder, and tertiary prevention at limiting the long-term sequelae and consequences of the disorder [10]. An alternative approach uses the level of risk of a disorder to classify prevention programs. Universal interventions are directed at whole populations at average risk, selective interventions are directed to groups at increased average risk, and indicated interventions to individuals with early emerging problems [6]. According to the setting in which interventions are delivered, universal programs may be classified in school, family, and multi-component programs settings [11-13]. Schools are the ideal location for promoting health services for young people $[14,15]$. School-based prevention programs can be delivered as school lessons (specific curricula), or behaviour management programs. They comprise educational programs, psychosocial programs, or a combination of them, with the objective of reducing the risk of heavy alcohol consumption. Psychosocial interventions are aimed at developing the skills to reduce this risk, whereas educational interventions at increasing the awareness of the potential dangers of drinking [11]. In school settings, universal prevention programs comprise awareness education, social and peer resistance skills, normative feedback, or development of behavioural norms and positive peer affiliations [11]. In recent years computer- and internet-based prevention programs have been also developed [16]. However, it is not clear whether these programs are really effective.

\section{AIMS OF THE STUDY}

The present study was aimed at reviewing the evidence of effectiveness of universal school-based alcohol prevention programs in reducing alcohol consumption or increasing knowledge on its negative effects in adolescents in studies conducted in Europe to possible identify the typology of programs with the best evidence of effectiveness to be proposed in a future European project.

\section{METHODS}

\section{Selection of Meta-Analyses}

An initial systematic search was conducted on PubMed/Medline using the following keywords: "school based prevention program and alcohol OR alcohol OR drugs OR marijuana OR tobacco OR addiction", using the filter "metaanalysis". Only meta-analyses assessing the effectiveness of interventions delivered at schools to prevent/reduce alcohol consumption or alcohol and other substance use or change the attitudes, knowledge, harms, and intentions to consume alcohol and other substances among young people (aged 019 years old) were included. Articles were excluded if they were unrelated to the topic, written in language other than English, were letters or comments, and if programs were implemented at home or community or delivered to college or university students. Abstracts of retrieved articles and full copies of potentially relevant articles were obtained to determine if they met the inclusion criteria. References of retrieved articles were also examined to identify other possible relevant studies.

\section{Selection of Trials}

To collect information on trails conducted after the publication of the selected meta-analysis, a subsequent systematic search was conducted on PubMed/Medline with timeline August 2010 to June 2014 using the following keywords: "school based prevention program and alcohol OR alcohol OR drugs OR marijuana OR tobacco OR addiction", using the filter "randomized controlled trials" (RCTs). Also in this search only RCTs assessing the effectiveness of interventions delivered at schools to prevent/reduce alcohol consumption or alcohol and other substance use or change the attitudes, knowledge, harms, and intentions to consume alcohol and other substances among young people (aged 0-19 years old) were included. Articles were excluded if they were unrelated to the topic, written in language other than English, were letters or comments, and if programs were implemented at home or community or delivered to college or university students. Abstracts of retrieved articles and full copies of potentially relevant articles were obtained to determine if they met the inclusion criteria. References of retrieved articles and reviews on the topic were also examined to identify other possible relevant studies. An expert author from another country (MCA) was involved with the aim to identify additional studies.

\section{RESULTS}

\section{Selection of Meta-analyses}

Fig. (1) shows the flowchart of the search strategy and study selection of meta-analyses. Overall, 21 articles were assessed. Among them, 11 articles were removed because they were a duplication of other studies already included. Another meta-analysis was identified through manual search of retrieved references. Among these meta-analyses, 6 were removed because they were unrelated to the topic. Among the remaining 5 articles, 4 were excluded because a more recently meta-analysis was found. Exclusion's reasons are shown in Table 1. The search was performed in June 2014.

\section{Selection of Trials}

Fig. (2) shows the flowchart of the search strategy and study selection of RCTs. The search was performed in June 2014. Overall, 93 articles were found. Among them, 30 articles were removed because they were a duplication of other studies. To the remaining 63 articles, other 5 articles were added, identified through manual search of retrieved references. Among these 68 articles, 56 were excluded for different reasons (e.g. they were not RCTs, were not related to the topic, and so on). Exclusion's reasons are shown in Table 2.

\section{Description of the Selected Meta-Analysis}

The selected meta-analysis reviewed 53 RCTs randomized trials in which universal intervention programs were delivered to students aged up to 18 years published up to 


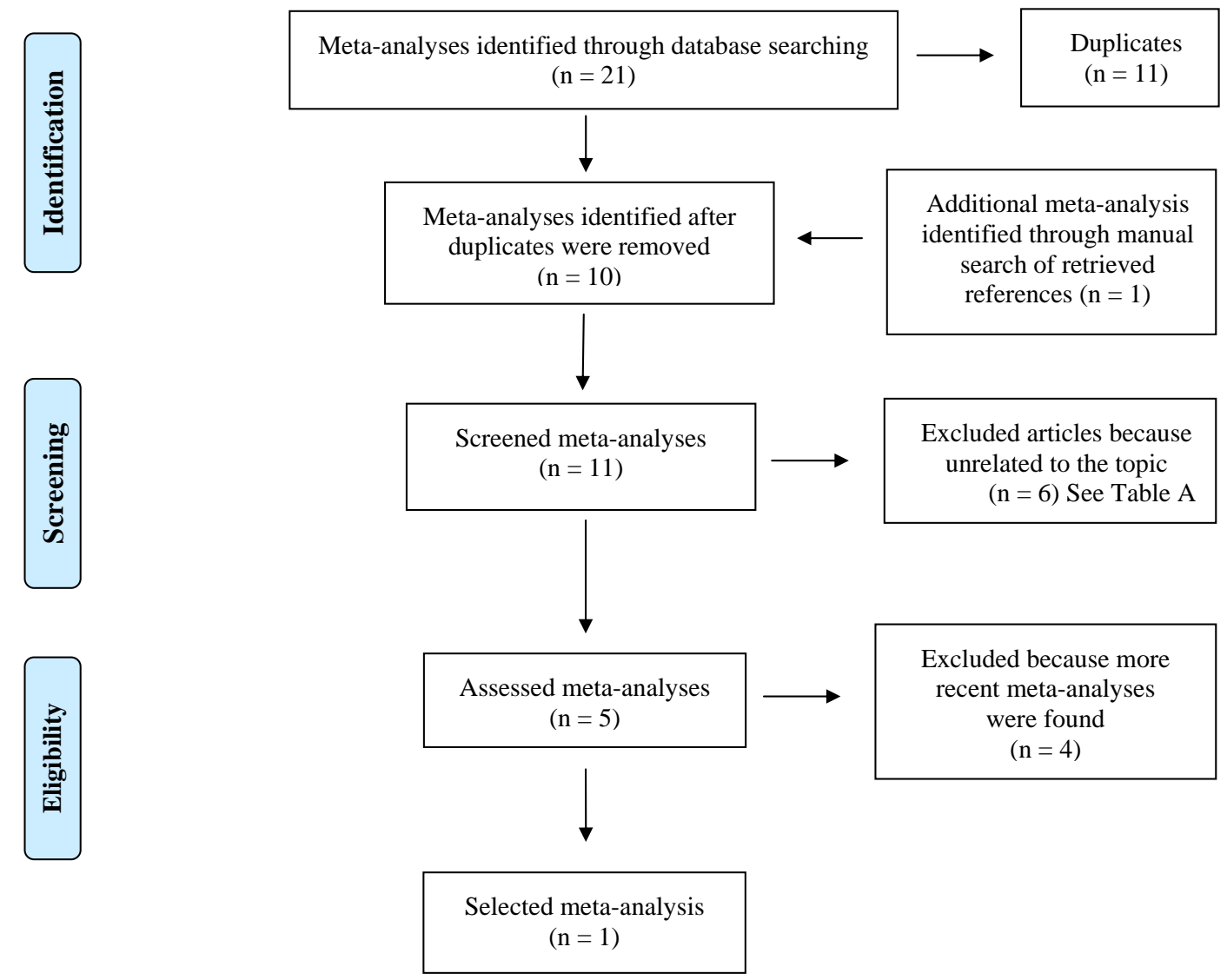

Fig. (1). Flowchart indicating search strategy and classification of meta-analyses.
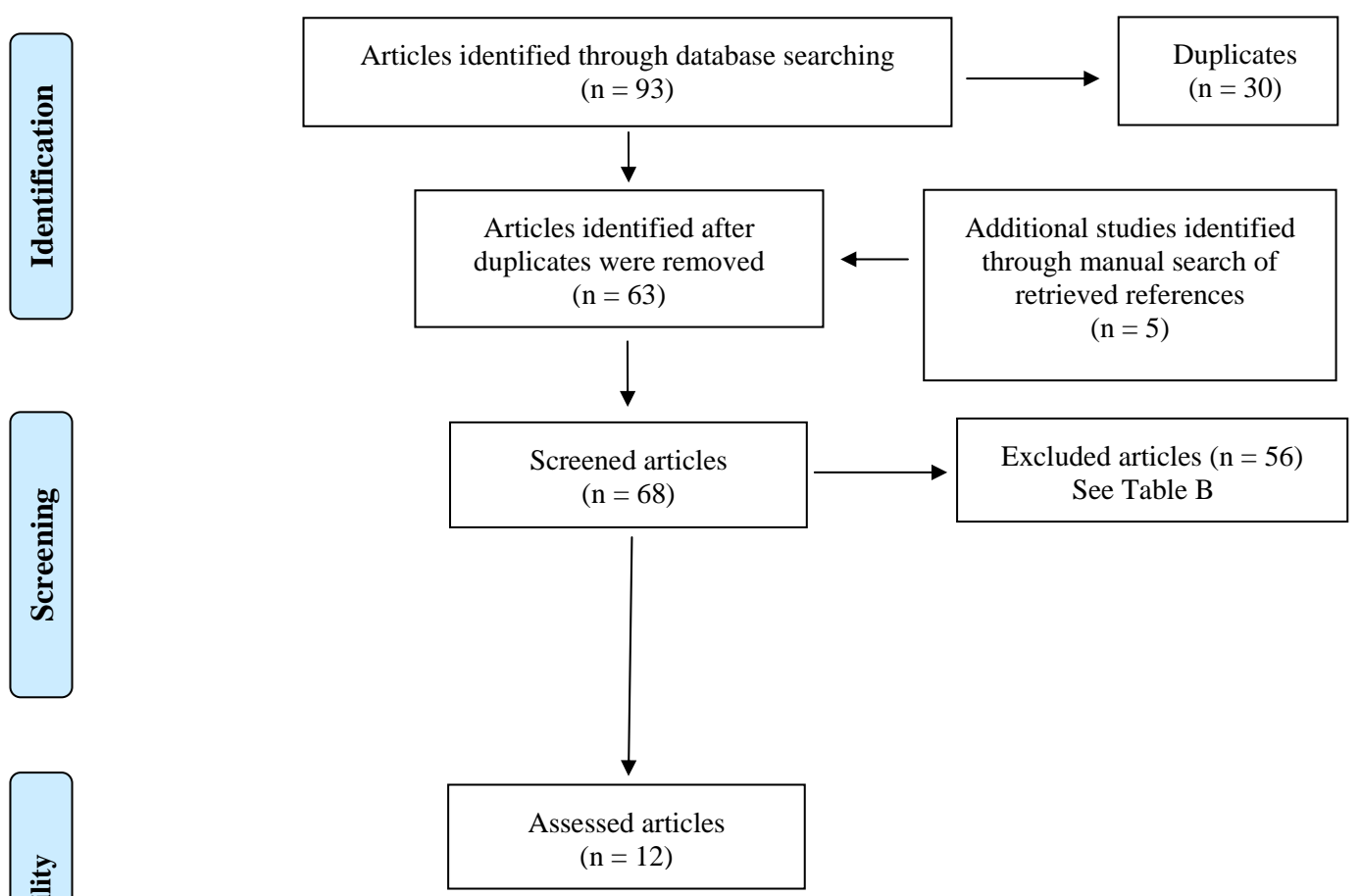

Fig. (2). Flowchart indicating search strategy and classification of articles. 
July 2010 [11]. Among these 53 trials, 11 were specifically focused in preventing alcohol use and the other 42 the consumption of alcohol and other substances. Due to the heterogeneity in interventions, populations, and outcomes, the trials were only summarized qualitatively. The results indicated that 23 out of 53 trials showed some evidence of effectiveness compared to control groups, whereas in the remaining 30 trials, there was no statistically difference in the effectiveness between the intervention programs and the control groups. The majority of these trials was conducted in North America and Australia (47 trials out of 53, equal to $88.7 \%$ ), and it was not possible to identify the characteristics to distinguish trials with positive effects from those with no effects. According to the conclusions of this meta-analysis, certain generic psychosocial and developmental prevention programs can be effective and could be considered as policy and practice options. In Europe, these include the Unplugged program and the Good Behaviour Game [11].

Table 1. Excluded meta-analyses (ordered by study ID).

\begin{tabular}{|c|c|c|}
\hline$\#$ & References & Reason for exclusion \\
\hline \hline 1 & {$[31]$} & A more recent meta-analysis was found \\
\hline 2 & {$[32]$} & A more recent meta-analysis was found \\
\hline 3 & {$[33]$} & College's students \\
\hline 4 & {$[34]$} & College's students \\
\hline 5 & {$[35]$} & A more recent meta-analysis was found \\
\hline 6 & {$[36]$} & A more recent meta-analysis was found \\
\hline 7 & {$[37]$} & Only cannabis \\
\hline 8 & {$[38]$} & Only smoking \\
\hline 9 & {$[39]$} & Only smoking \\
\hline 10 & {$[40]$} & College's students \\
\hline
\end{tabular}

Table 2. Excluded articles (ordered by study ID).

\begin{tabular}{|c|c|c|}
\hline$\#$ & References & Reason for exclusion \\
\hline \hline 1 & {$[41]$} & Only tobacco \\
\hline 2 & {$[42]$} & Only tobacco; Community-based intervention \\
\hline 3 & {$[43]$} & No related to the topic \\
\hline 4 & {$[44]$} & No related to the topic \\
\hline 5 & {$[45]$} & Only tobacco \\
\hline 6 & {$[46]$} & Trial already described by [17] \\
\hline 7 & {$[47]$} & Trial evaluated by [11] \\
\hline 8 & {$[48]$} & Trial already described by [18] \\
\hline 9 & {$[49]$} & Community-based intervention \\
\hline 10 & {$[50]$} & Selective prevention to at-risk adolescents \\
\hline 11 & {$[51]$} & Only tobacco \\
\hline 12 & {$[52]$} & Not delivered to students \\
\hline 13 & {$[53]$} & \\
\hline
\end{tabular}

\begin{tabular}{|c|c|c|}
\hline 14 & {$[54]$} & No related to the topic \\
\hline 15 & {$[55]$} & Pilot evaluation \\
\hline 16 & {$[56]$} & No related to the topic \\
\hline 17 & {$[57]$} & No related to the topic \\
\hline 18 & {$[58]$} & No related to the topic \\
\hline 19 & {$[59]$} & Selective prevention to at-risk adolescents \\
\hline 20 & {$[60]$} & No related to the topic \\
\hline 21 & {$[61]$} & Only tobacco \\
\hline 22 & {$[62]$} & Only illegal substances \\
\hline 23 & {$[63]$} & No related to the topic \\
\hline 24 & {$[64]$} & No related to the topic \\
\hline 25 & {$[65]$} & Not in English \\
\hline 26 & {$[66]$} & Community-based intervention \\
\hline 27 & {$[67]$} & Study protocol \\
\hline 28 & {$[68]$} & Only illegal substances \\
\hline 29 & {$[69]$} & Only tobacco \\
\hline 30 & {$[70]$} & University students \\
\hline 31 & {$[71]$} & Study protocol \\
\hline 32 & {$[72]$} & Only tobacco \\
\hline 33 & {$[73]$} & Study protocol \\
\hline 34 & {$[74]$} & Home-based prevention program \\
\hline 35 & {$[75]$} & $\begin{array}{l}\text { Only cannabis; Selective prevention to } \\
\text { at-risk adolescents }\end{array}$ \\
\hline 36 & {$[76]$} & No related to the topic \\
\hline 37 & {$[77]$} & Study protocol \\
\hline 38 & {$[78]$} & Only tobacco \\
\hline 39 & {$[79]$} & Pilot study \\
\hline 40 & {$[80]$} & Study protocol \\
\hline 41 & {$[81]$} & No related to the topic \\
\hline 42 & {$[82]$} & Personality-Targeted Interventions \\
\hline 43 & {$[83]$} & Study protocol \\
\hline 44 & {$[84]$} & No related to the topic \\
\hline 45 & {$[85]$} & Only tobacco \\
\hline 46 & {$[86]$} & $\begin{array}{l}\text { Community-based intervention; Selective } \\
\text { prevention to at-risk adolescents }\end{array}$ \\
\hline 47 & {$[87]$} & Pilot study \\
\hline 48 & {$[88]$} & Adults \\
\hline 49 & {$[89]$} & Selective prevention to at-risk adolescents \\
\hline 50 & {$[90]$} & Only tobacco \\
\hline 51 & {$[91]$} & Analysis of a trial; Only tobacco \\
\hline 52 & {$[92]$} & No related to the topic \\
\hline 53 & {$[93]$} & $\begin{array}{l}\text { Selective prevention to at-risk adolescents; } \\
\text { Only cannabis }\end{array}$ \\
\hline 54 & {$[94]$} & Selective prevention to at-risk adolescents \\
\hline 55 & {$[95]$} & No related to the topic \\
\hline 56 & {$[96]$} & No related to the topic \\
\hline
\end{tabular}




\section{Description of the Selected RCTs}

Twelve RCTs were included in this review article, in which universal prevention programs were delivered at schools, to students aged at baseline from 10 to 19 years (see Table 3) [17-28]. Six trials were conducted in North America $(50.0 \%)[18,20,21,24,27,28], 5$ in Europe (41.7\%) $[17,19,22,23,25]$, and 1 in China (8.3\%) [26]. The number of students recruited in these trials ranged from 416 [25] to 7,079 subjects [17]. The proportion of girls amongst the included trials ranged from 43.4 [27] to $64.0 \%$ [28].

In 2 trials $(16.7 \%)$, the target of the intervention programs was a reduction of alcohol use [19, 20], in 1 trial $(8.3 \%)$ the reduction of alcohol use and alcohol-related problems [17]; in 2 trials (16.7\%), a reduction of the use of alcohol and other substances [21, 22]; in 3 trials $(25.0 \%)$, the target was an increase of the perception of harms related to alcohol use or other substances or an increase of knowledge $[18,23,24]$; in 2 trials $(16.7 \%)$, the reduction of the use of alcohol and other substances, and their related problems $[26,27]$. Another trial evaluated the onset of consumption of alcohol and other substances [25]. Finally, in one study, the target of the intervention program was the reduction of the use of alcohol and other drugs and an increase of healthy behaviors [28]. The outcome measures of alcohol use as well that of other substances differed across the trials.

\section{Control Groups}

In the majority of trials (8, equal to $66.7 \%$ ), the effectiveness of prevention programs was compared to that of an usual health education (standard curriculum) $[17-19,22,23$, 25-27]. In 2 trials, the control groups of students were only assessed [20, 21]. In 1 trial, the control group students were in waiting list for the prevention program [24]. Finally, in 1 trial, the control group of students received standard care [28].

\section{Brief Description of the Prevention Programs}

The 12 trials evaluated the effectiveness of different universal school-based intervention programs. Namely, 3 (25.0\%) evaluated the effectiveness of the Unplugged program [17, 22, 23], 1 trial the Adventure program [19], 1 trial the SUCCESS program [18], 1 trial the CHOICE program [20], 1 trial an internet-based intervention [21], 1 trial the Media Detective program [24], 1 trial an adaptation of Motivational interview [25], 1 trial the P.A.T.H.S. intervention [26], and 1 trial a Project Active [28]. One trial compared a program called Towards No Drug Abuse to a Motivational Interviewing [27]. All these programs are aimed at enhancing resilience in young people by increasing knowledge about the harms of alcohol consumption and promoting better coping skill among children and their parents [19].

\section{Unplugged Program}

The Unplugged program targets all substances of abuse, with a special focus on alcohol, tobacco, and marijuana [22]. The intervention is usually delivered by trained teachers in twelve lessons over the course of one school-year. It focuses on knowledge and attitudes (4 units), interpersonal skills (4 units), and intrapersonal skills (4 units). Unplugged Teacher's Handbook and the Student's Workbook are avail- able in several language versions, available at: http://www.eudap.net

\section{SUCCESS Program}

The SUCCESS program includes 6-8 lessons delivered by professional counselors to small groups, on the following 4 topics: (1) Being an adolescent, (2) alcohol, tobacco, and other drugs, (3) family pressures and problems and (4) skills for copying [18].

\section{Adventure Program}

The Adventure program (Teacher - delivered personality targeted intervention for substance misuse) is based on the premise that personality-specific skills training to improve management of one's personality vulnerability will reduce the likelihood that alcohol will be used for coping [19].

\section{CHOICE Program}

The CHOICE program consists in sessions focused on providing normative feedback on alcohol and marijuana use, challenging unrealistic beliefs about substances, resisting pressure to use substances through the use of role play, discussing potential benefits of both cutting down and stopping use and discussing risky situations and coping strategies (e.g., getting social support, learning how to avoid certain high-risk situations) [20].

\section{Internet-Based Intervention}

The internet-based intervention requires very little faculty and staff time [21]. It has been reported that this typology of prevention programs may overcome some limits to implementation of "classical" school-based programs such as the scarce resources in terms of time of teachers to deliver prevention programs [16]. Indeed, computer- and internetbased prevention programs may be used when teaching time is limited.

\section{Media Detective Program}

The Media Detective program consists in 10 lessons aimed at preventing substance use, increasing children's critical thinking skills about media messages and reducing intent to use tobacco and alcohol products [24].

\section{Motivational Interviewing}

Motivational Interviewing (MI) is an individualized intervention aimed at helping the participant to explore their own behavior. Emphasis is given to perceptions of risk and problem recognition, concerns, and consideration of change. An adopted MI also includes material specifically for primary prevention purposes such as discussion of hypothetical situations in which drugs are offered for the first time, and reasons for not using specific substances [25].

\section{P.A.T.H.S. Program}

The Project P.A.T.H.S. (Positive Adolescent Training through Holistic Social Programmes) is aimed to promote positive development and reduce the risk or problem [26]. 
Table 3. School-based prevention programs for alcohol and other substances $(n=12)$.

\begin{tabular}{|c|c|c|c|c|c|c|c|c|}
\hline & Study & Location & Type of intervention & Evaluations & Outcomes & $\begin{array}{l}\text { Total sample } \\
\text { Age } \\
\text { Range or mean } \\
\text { (SD) in years } \\
\text { Gender ( } ~+\text { in \% } \\
\text { of sample) }\end{array}$ & $\begin{array}{l}\text { Samples } \\
\text { Gender }(q \\
\text { in \% of } \\
\text { sample) }\end{array}$ & Results \\
\hline 1 & {$[17]$} & $\begin{array}{l}143 \text { Schools in } \\
7 \text { European } \\
\text { countries }\end{array}$ & $\begin{array}{l}\text { I: Unplugged } \\
\text { C: Usual health educa- } \\
\text { tion }\end{array}$ & 18 Months after & $\begin{array}{l}\text { 1) Use of alcohol } \\
\text { 2) Alcohol related } \\
\text { problems }\end{array}$ & $\begin{array}{l}\mathrm{n}=7,079 \\
\text { Age Range: } 12-14\end{array}$ & $\begin{array}{l}\mathrm{I}: \mathrm{n}=3,547 \\
\text { q: } 48 \% \\
\mathrm{C}: \mathrm{n}=3,532 \\
\text { : } 51 \%\end{array}$ & 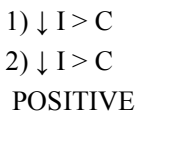 \\
\hline 2 & [18] & $\begin{array}{l}14 \text { Schools in } \\
\text { Washington State } \\
\text { (US) }\end{array}$ & $\begin{array}{l}\text { I: SUCCESS } \\
\text { C: Usual health educa- } \\
\text { tion }\end{array}$ & 18 Months after & $\begin{array}{l}\text { Perceptions of harm } \\
\text { from: } \\
\text { 1) Alcohol } \\
\text { 2) Marijuana }\end{array}$ & $\begin{array}{l}\mathrm{n}=1,711+: 50 \% \\
\text { Age Mean: } 16.7 \\
(1,4)\end{array}$ & $\begin{array}{l}I: n=743 \\
C: n=968\end{array}$ & $\begin{array}{l}\text { 1) } \uparrow \mathrm{I}>\mathrm{C} \\
\text { 2) } \uparrow \mathrm{I}>\mathrm{C} \\
\text { Other outcomes } \\
\mathrm{C}>\mathrm{I} \\
\text { MIXED }\end{array}$ \\
\hline 3 & [19] & $\begin{array}{l}148 \text { Schools in } \\
\text { London (UK) }\end{array}$ & $\begin{array}{l}\text { I: Adventure } \\
\text { C: Usual health educa- } \\
\text { tion } \\
\text { Students divided into } \\
\text { High risk } \\
\text { Low risk }\end{array}$ & $\begin{array}{l}6 \text { Months after } \\
12 \text { Months after } \\
18 \text { Months after } \\
24 \text { Months after }\end{array}$ & $\begin{array}{l}\text { 1) Use of alcohol } \\
\text { 2) Binge drinking } \\
\text { 3) Problem drinking }\end{array}$ & $\begin{array}{l}\mathrm{n}=2,293+\text { 证 } \\
\text { Age Mean: } 13.7 \\
(0.3)\end{array}$ & $\begin{array}{l}\text { High risk } \\
\mathrm{I}: \mathrm{n}=588 \\
\mathrm{C}: \mathrm{n}=437 \\
\text { Low risk } \\
\mathrm{I}: \mathrm{n}=752 \\
\mathrm{C}: \mathrm{n}=516\end{array}$ & $\begin{array}{l}\text { 1) } \downarrow \text { I }>C \\
\text { 2) } \downarrow \text { I }>C \\
\text { 3) } \downarrow \text { I }>C \\
\text { POSITIVE }\end{array}$ \\
\hline 4 & {$[20]$} & $\begin{array}{l}16 \text { Schools in } \\
\text { California (US) }\end{array}$ & $\begin{array}{l}\text { I: CHOICE } \\
\text { C: AO }\end{array}$ & $\begin{array}{l}\text { 6- } 7 \text { Months } \\
\text { after }\end{array}$ & $\begin{array}{l}\text { Use of alcohol } \\
\text { 1) Lifetime } \\
\text { 2) Past month }\end{array}$ & $\begin{array}{l}\mathrm{n}=9,528+9: 51 \% \\
\text { Age: NA }\end{array}$ & $\begin{array}{l}\mathrm{I}: \mathrm{n}=4,689 \\
\text { q: } 50 \% \\
\mathrm{C}: \mathrm{n}=4,243 \\
\text { : } 51 \%\end{array}$ & $\begin{array}{l}\text { 1) } \uparrow \mathrm{I}=\mathrm{C} \\
\text { 2) } \uparrow \mathrm{I}=\mathrm{C} \\
\text { NEGATIVE }\end{array}$ \\
\hline 5 & {$[21]$} & 22 Schools (US) & $\begin{array}{l}\text { I: Internet-based } \\
\mathrm{C}: \mathrm{AO}\end{array}$ & $\begin{array}{l}3 \text { Months after } \\
14 \text { Months after }\end{array}$ & $\begin{array}{l}\text { Use of alcohol and } \\
\text { other drugs }\end{array}$ & $\begin{array}{l}\mathrm{n}=1,590+9: 47 \% \\
\text { Age Range: } 10-14\end{array}$ & $\begin{array}{l}\mathrm{I}: \mathrm{n}=865+: \\
49 \% \\
\mathrm{C}: \mathrm{n}=725 \circ: \\
46 \%\end{array}$ & $\begin{array}{l}3 \text { Months after } \\
\downarrow \text { I }>\text { C } \\
12 \text { Months after } \\
\downarrow \text { I }<\mathrm{C} \\
\text { MIXED }\end{array}$ \\
\hline 6 & {$[22]$} & $\begin{array}{l}8 \text { Schools in } \\
\text { Czech Republic }\end{array}$ & $\begin{array}{l}\text { I: Unplugged } \\
\text { C: Usual health educa- } \\
\text { tion }\end{array}$ & $\begin{array}{l}1 \text { Month after } \\
3 \text { Months after } \\
12 \text { Months after } \\
15 \text { Months after } \\
24 \text { Months after }\end{array}$ & $\begin{array}{l}\text { In the past 30- days: } \\
\text { 1) Drunkenness } \\
\text { 2) Smoking } \\
\text { 3) Cannabis }\end{array}$ & $\begin{array}{l}\mathrm{n}=1,753 \text { + }: 49 \% \\
\text { Age Range: } 11-13\end{array}$ & $\begin{array}{l}I: n=914 \\
C: n=839\end{array}$ & $\begin{array}{l}\text { 1) } \downarrow \text { I }>C \\
\text { 2) } \downarrow \text { I }>C \\
\text { 3) } \downarrow \text { I }>C \\
\text { POSITIVE }\end{array}$ \\
\hline 7 & {$[23]$} & $\begin{array}{l}143 \text { Schools in } \\
\text { Europe }\end{array}$ & $\begin{array}{l}\text { I: Unplugged } \\
\text { C: Usual health educa- } \\
\text { tion }\end{array}$ & 3 Months after & $\begin{array}{l}\text { Alcohol and other } \\
\text { drugs: } \\
\text { 1) Positive attitudes } \\
\text { 2) Positive beliefs } \\
\text { 3) Knowledge } \\
\text { 4) Refusal skills } \\
\text { 5) Negative beliefs }\end{array}$ & $\begin{array}{l}\mathrm{n}=6,370+: 48 \% \\
\text { Age Mean: } 13.2 \\
(1.0)\end{array}$ & $\mathrm{n}=\mathrm{NA}$ & 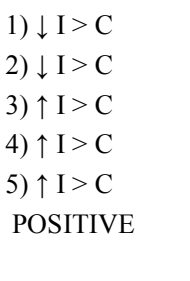 \\
\hline 8 & [24] & $\begin{array}{l}12 \text { Schools in } \\
\text { North Carolina } \\
\text { (US) }\end{array}$ & $\begin{array}{l}\text { I: Media Detective } \\
\text { Program } \\
\text { C: WL }\end{array}$ & $\begin{array}{l}\text { At the end of the } \\
\text { intervention }\end{array}$ & $\begin{array}{l}\text { 1) Interest in alcohol } \\
\text { 2) Intention to use } \\
\text { alcohol and tobacco } \\
\text { 3) Self- efficacy of } \\
\text { refuse substances }\end{array}$ & $\begin{array}{l}\mathrm{n}=679+: 51 \% \\
\text { Age Range: } 7-13 \\
\text { Mean: } 9.4(1.1)\end{array}$ & $\begin{array}{l}I: n=344 \\
C: n=335\end{array}$ & $\begin{array}{l}\text { 1) } \downarrow \text { I }>C \\
\text { 2) } \downarrow \text { I }>C \\
\text { 3) } \uparrow \text { I }>C \\
\text { POSITIVE }\end{array}$ \\
\hline 9 & {$[25]$} & $\begin{array}{l}12 \text { Colleges in } \\
\text { London (UK) }\end{array}$ & $\begin{array}{l}\text { I: Adaptation of Moti- } \\
\text { vational Interview } \\
\text { C: Usual health educa- } \\
\text { tion }\end{array}$ & $\begin{array}{l}3 \text { Months after } \\
12 \text { Months after }\end{array}$ & $\begin{array}{l}\text { Onset of: } \\
\text { 1) Alcohol } \\
\text { 2) Cigarette } \\
\text { 3) Cannabis }\end{array}$ & $\begin{array}{l}\mathrm{n}=416 \\
\text { Age Range: } 16-19\end{array}$ & $\begin{array}{l}\mathrm{I}: \mathrm{n}=206 \\
q: 45 \% \\
\mathrm{C}: \mathrm{n}=210 \text { 界: } \\
48 \%\end{array}$ & $\begin{array}{l}\text { 1) } \leftrightarrow \mathrm{I}=\mathrm{C} \\
\text { 2) } \leftrightarrow \mathrm{I}=\mathrm{C} \\
\text { 3) } \downarrow \text { I }<\mathrm{C} \\
\text { POSITIVE }\end{array}$ \\
\hline
\end{tabular}


(Table 3) contd....

\begin{tabular}{|c|c|c|c|c|c|c|c|c|}
\hline & Study & Location & Type of intervention & Evaluations & Outcomes & $\begin{array}{l}\text { Total sample } \\
\text { Age } \\
\text { Range or mean } \\
\text { (SD) in years } \\
\text { Gender ( } q \text { in \% } \\
\text { of sample) }\end{array}$ & $\begin{array}{l}\text { Samples } \\
\text { Gender }(q \\
\text { in \% of } \\
\text { sample) }\end{array}$ & Results \\
\hline 11 & [27] & $\begin{array}{l}24 \text { Schools in } \\
\text { South California } \\
\text { (US) }\end{array}$ & $\begin{array}{l}\text { I } 1: \text { TND } \\
\text { I } 2: \text { TND + MI } \\
\text { C: Usual health educa- } \\
\text { tion }\end{array}$ & 1 Year after & $\begin{array}{l}\text { Use of: } \\
\text { 1) Alcohol } \\
\text { 2) Hard drug } \\
\text { 3) Cigarette }\end{array}$ & $\begin{array}{l}\mathrm{n}=1,186 \text { }: 43 \% \\
\text { Age Mean: } 16.8 \\
(0.9)\end{array}$ & $\begin{array}{l}\text { I } 1: n=401 \\
\text { I } 2: n=392 \\
\text { C: } n=393\end{array}$ & $\begin{array}{l}\text { 1) } \downarrow \text { I1 }=\mathrm{I} 2>\mathrm{C} \\
\text { 2) } \downarrow \text { I1 }=\mathrm{I} 2>\mathrm{C} \\
\text { 3) } \downarrow \mathrm{I} 1=\mathrm{I} 2>\mathrm{C} \\
\text { POSITIVE }\end{array}$ \\
\hline 12 & [28] & $\begin{array}{l}2 \text { Schools in Flor- } \\
\text { ida (US) }\end{array}$ & $\begin{array}{l}\text { I: BI } \\
\text { C: SC }\end{array}$ & 3 Months after & $\begin{array}{l}\text { Use of } \\
\text { 1) Alcohol } \\
\text { 2) Cigarettes } \\
\text { 3) Marijuana }\end{array}$ & $\begin{array}{l}\mathrm{n}=479 \\
\text { Age Mean } 17.0 \\
(0.82)\end{array}$ & $\begin{array}{l}\text { I: } \mathrm{n}=237+\text { P: } \\
59 \% \\
\text { C: } \mathrm{n}=242+: \\
64 \%\end{array}$ & $\begin{array}{l}\downarrow \mathrm{I}>\mathrm{C} \\
\leftrightarrow \mathrm{I}=\mathrm{C} \\
\leftrightarrow \mathrm{I}=\mathrm{C} \\
\text { MIXED }\end{array}$ \\
\hline
\end{tabular}

Legend: AO: Assessed only, BI: Brief Intervention, C: Control, DFC: Delayed feedback Control, EFC: Educational Feedback Control, I: Intervention, MI: Motivational Interviewing, NA: Not Available, P.A.T.H.S.: Positive Adolescent Training through Holistic Social Programmers, RCT: Randomized controlled trial, SC: Standard Care, SUCCESS: Schools Using Coordinated Community Efforts to Strengthen Students, TND: Towards No Drug Abuse, WL: Waiting List.

\section{Project Towards No Drug Abuse (TND) program}

Project Towards No Drug Abuse (TND) program is a 12session school-based substance abuse prevention program developed for older, at-risk teens, based on a motivation, skills, and decision-making model [27].

\section{Project Active}

The Project Active is a 9-item life skills screen assessing target health behaviors, a one-on-one consultation with slides presenting positive image feedback tailored to screen results, a set of concrete behavioral recommendations for enhancing future fitness, and a personal fitness goal setting and commitment strategy linking positive image attainment with specific health behavior change [28]. The brief intervention was administered during regular school hours in designated study spaces.

\section{EVIDENCE OF EFFECTIVENESS OF THE PREVEN- TION PROGRAMS}

\section{Unplugged Program}

Participation to Unplugged program produced positive results. One trial found that adolescents who participated to this program, compared to adolescents of the control group, significantly decreased the risk of reporting alcohol-related problems $(\mathrm{OR}=.78,95 \%$; confidence intervals $[\mathrm{CI}]=.63$ $.98)$ but not the risk for alcohol consumption $(\mathrm{OR}=.93,95 \%$ $\mathrm{CI}=$.79-1.09) [17]. However, among adolescents of the Unplugged group, nondrinkers and occasional drinkers at baseline progressed toward frequent drinking less often than those of control group [17]. A recent study provided another statistical analysis of these results [29]. Namely, three months after the end of the program, adolescents who par- ticipated to Unplugged program had a lower increase in the prevalence of use of tobacco and cannabis, and of frequency of recent drunkenness episodes, compared to controls. Significant effects were detected for daily cigarette use, for any and frequent episodes of drunkenness in the past thirty days, while a marginal statistical effect was detected for cannabis use. For instance, 3 months after the intervention, prevalence of frequent drunkenness was equal to $3.9 \%$ and $2.5 \%$ of adolescents who participated to the control program and the Unplugged, respectively with a reduction equal of $31 \%(\mathrm{P}>$ $.05)$; 15 months after, prevalence of frequent drunkenness was equal to $6.4 \%$ and $3.8 \%$ of adolescents who participated to the control program and the Unplugged, respectively with a reduction equal of $38 \%(\mathrm{P}>.05)$.

Another study found that adolescents who participated to this program achieved statistically significant effects at the final follow-up for any smoking $(\mathrm{OR}=.75,99.2 \% \mathrm{CI} .65-$ $.87)$, daily smoking (OR $=.62,99.2 \% \mathrm{CI} .48-.79)$, heavy smoking $(\mathrm{OR}=.48,99.2 \% \mathrm{CI} .28-.81)$, any cannabis use $(\mathrm{OR}=.5799 .2 \% \mathrm{CI} .42-.77)$, frequent cannabis use $(\mathrm{OR}=$ $.57,99.2 \%$ CI .36-.89), and any drug use (OR $=.78,99.2 \%$ CI .65-.94), compared to adolescents of the control group [22].

The last trial found that the effects obtained by adolescents who participated to Unplugged program were generally weak and some of them were only marginally significant [23]. Namely, adolescents of the intervention group compared to those of the control group, endorsed less positive attitudes toward drugs, positive beliefs about cigarettes, alcohol, and cannabis, and the normative perception of peers using tobacco and cannabis. They also increased in knowledge about all substances and refusal skills toward tobacco. Decreased positive attitudes toward drugs, increase in refusal 
skills, and reappraisal of norms about peer using tobacco and cannabis appeared to mediate the effects of the program on the use of substances.

\section{Adventure Program}

Also participation to Adventure program produced positive results. High risk (HR) adolescents who participated to this program had significant effects compared to HR adolescents of the control group [drinking rates $(\mathrm{P}=.03)$; binge drinking rates $(\mathrm{P}=.03)$, growth in binge drinking $(\mathrm{P}=.009)$, problem drinking $(\mathrm{P}=.02)$; drinking quantity $(\mathrm{P}=.04)$, growth in drinking quantity $(\mathrm{P}=.02)$, and growth in binge drinking frequency $(\mathrm{P}=.047)$ [19]. Some significant effects were also obtained by low risk (LR) adolescents who participated to the Adventure program compared to LR adolescents of the control group [drinking rates $(\mathrm{P}=.049)$ and growth of binge drinking $(\mathrm{P}=.001)]$.

\section{Media Detective Program}

Media Detective program achieved better results than control group too. Namely adolescents who participated in this intervention program reported significantly less interest in alcohol-branded merchandise than adolescents in the control group $(\mathrm{P}<.0001)$ [24]. Students who were in the Media Detective group and had used alcohol or tobacco in the past reported significantly less intention to use $(\mathrm{P}<.0001)$ and more self-efficacy $(\mathrm{P}<.0001)$ to refuse substances than students who were in the control group and had previously used alcohol or tobacco.

\section{P.A.T.H.S. Program}

Also adolescents who participated to P.A.T.H.S program displayed lower levels of substance abuse than did the control students $(\mathrm{P}<.05)$ [26]. Participants who regarded the program also showed lower levels of problem behavior and delinquent behavior than did the control students $(\mathrm{P}<.05)$.

\section{TND Program}

TND achieved better results than control group too. Namely, adolescents who participated to TND program or TND+MI program achieved significant reductions in alcohol use, hard drug use, and cigarette smoking relative to controls but there were no statistically significant differences between the TND+MI and TND-only groups [27]. Looking at TND versus the SCC, there were one-tailed effects of $\mathrm{P}<.05$ on 30-day alcohol use $(\mathrm{P}<.05)$, drunk on alcohol $(\mathrm{P}<.05)$, and hard drug use $(\mathrm{P}<.05)$. Also, there were effects on number of times for use of cigarettes $(\mathrm{P}<.05)$, alcohol $(\mathrm{P}<.05)$, and hard drugs $(\mathrm{P}<.05)$. Further analysis with the two index indicators revealed that any TND programming generated a statistically significant effect on both the hard drug use index $(\mathrm{P}=.05)$ and on the substance use index $(\mathrm{P}=.05)$. The TND+MI programming did not significantly enhance the effect on the hard drug use index $(\mathrm{P}=0.27)$ or the substance use index $(\mathrm{P}=.38)$ over TND-only programming. No effects were found on risky sexual behavior.

\section{Active Program}

Participants receiving the Project Active program showed a significant reduction in quantity $\times$ frequency of alcohol use, and increases in fruit and vegetable consumption and frequency of relaxation activities, compared to those receiving the control $(\mathrm{P}=.01)$ [28]. No effects were found on cigarette and marijuana use, exercise and sleep. Effect sizes were small with alcohol use cessation effects reaching medium size.

\section{CHOICE Program}

Conversely participation to the CHOICE program did not induced positive results. Adolescents who participated to this program did not achieve significant effects in lifetime and past month alcohol consumption compared to adolescents of the control group $(\mathrm{P}=.20)$ [20]. From baseline to follow up, consumption and intention measures all increased (as expected of this age group); however, rates of consumption were lower among CHOICE participants compared to controls. Morever, it was calculated that the CHOICE program achieved statistical significance at school level [OR 0.70 ; number needed to treat (NNT): 14.8 (in a school where CHOICE is offered, 1 adolescent out of 15 prevents from initiating alcohol use during this time period)] [20]. Examination of school-wide effects indicated that rates of consumption and intentions to use alcohol were also significantly lower in CHOICE schools compared to control schools.

\section{Motivational Interviewing}

One trial found that adolescents who participated to MI did not achieve different results from those achieved by adolescents of standard curriculum [25]. Namely, there were no statistically significant between-group differences for either cigarette smoking or alcohol consumption outcomes. There were also no statistically significant between-group differences when the analyses were restricted to those who were already users of these substances upon entry to the study.

\section{SUCCESS Program}

Finally, participation to SUCCESS program produced a mixed pattern of results. Indeed, participation to this program significantly increased students' perceptions of harm resulting from alcohol use, whereas the control group's perception remained relatively constant $(\mathrm{P}<.05)$ [18]. Also perceptions of harm resulting from marijuana use significantly increased in the intervention group and decreased in the control group $(\mathrm{P}<.05)$ [18]. However, in the same study, other findings (peer support, perceptions about the prevalence and acceptability of alcohol use) were more favorable to control group than to Project SUCCESS.

\section{Internet-Based Intervention}

Also participation to an internet-based intervention produced a mixed pattern of results [21]. At the initial 3-month follow-up, the intervention produced significant reductions in the percentage of "ever-users" in middle schools who were using alcohol, tobacco, marijuana, and other drugs at initial follow-up. The same pattern occurred for those who were "current users" at baseline. At the 14-month follow-up, however, the treatment differences were no longer significant, even though the intervention group had a higher percentage of participants in Action/Maintenance. The general 
pattern of findings indicated the participants in the intervention group were more likely than the control group to reach Action/Maintenance at the 3-month follow-up but these effects diminished at 14-months, while the control group showed an increasing trajectory of students reaching Action/Maintenance over time [21].

\section{CONCLUSION}

The present study reviewed a meta-analysis published in 2011 [11] and 12 RCTs, published from August 2010 to date [17-28], in which school-based alcohol prevention programs were delivered to adolescents (0-19 years). The metaanalysis reviewed 53 RCTs. Globally, 23 trials (43.4\%) showed some evidence of effectiveness compared to control groups, whereas in the remaining 30 trials $(56.6 \%)$, there was no statistically difference in the effectiveness between the intervention programs and the control groups. Despite the majority of these trials was conducted in North America and Australia, according to the conclusions of this metaanalysis, in Europe, the Unplugged program should be one of the prevention programs to be suggested [11].

Among the other 12 RCTs selected by the present study [17-28], globally 2 trials (16.7\%) found that the prevention programs did not induce better results than control groups $[20,25], 3$ trials $(25.0 \%)$ produced a mixed pattern of results $[18,21,28]$, whereas 7 trials $(58.3 \%)$ found that adolescents who participated to a prevention program achieved better results compared with control groups [17, 18, 22-24, 26, 27].

The rate of effective programs found by the present study is lightly higher than that found by previous reviews articles $[6,11,30]$. Several differences may explain the different rates of effective prevention programs found by the present study compared to that found by Foxcroft and Tsertsvadze in 2011 [11]. The first explanation is constituted by a limit of the present study, the lack of the evaluation of possible risk of bias in included studies (e.g. the method of randomization, the instruments or questionnaires used for measurement of alcohol consumption, etc.). However, this kind of analysis was behind the aims of the present study.

Another possible reason of the higher rate of effective prevention programs found by the present study may be the different places where the trials were conducted, and the kind of prevention programs used in these places. Indeed, in the study conducted by Foxcroft and Tsertsvadze in 2011 [11], the majority of trials was conducted in North America, and only $11.3 \%$ in Europe. Conversely, in the present study, 5 out 12 trials (approximately 42\%) were conducted in Europe [17, 19, 22, 23, 25].

Interestingly, 3 out of these 5 European trials (60\%) evaluated the effectiveness of the Unplugged prevention program $[17,22,23]$. The 3 trials found that adolescents who participated to the Unplugged program achieved better results than adolescents of the control groups. Globally, the sample of adolescents was equal to more than 15,000 subjects. These findings show that, according to the results of the present study, Unplugged appears to be the prevention program more frequently adopted in Europe, and the one with the best evidence of effectiveness [17, 22, 23]. Further studies should be conducted to confirm these results.

\section{CONFLICT OF INTEREST}

The authors confirm that this article content has no conflict of interest.

\section{ACKNOWLEDGEMENTS}

Declared none.

\section{REFERENCES}

[1] Rehm J, Mathers C, Popova S, Thavorncharoensap M, Teerawattananon Y, Patra J. Global burden of disease and injury and economic cost attributable to alcohol use and alcohol-use disorders. Lancet 2009; 373(9682): 2223-33.

[2] Kuntsche E, Kuntsche S, Knibbe R, et al. Cultural and gender convergence in adolescent drunkenness: Evidence from 23 European and North American countries. Arch Pediatr Adolesc Med $2011 ; 165(2)$ : 152-8.

[3] Archie S, Zangeneh-Kazemi A, Akhtar-Danesh N. Concurrent binge drinking and depression among Canadian youth: prevalence, patterns, and suicidality. Alcohol 2012; 46(2): 165-72.

[4] Bava S, Tapert SF. Adolescent brain development and the risk for alcohol and other drug problems. Neuropsychol Rev 2010; 20(4): 398-413.

[5] Hermens DF, Lagopoulos J, Tobias-Webb J, et al. Pathways to alcohol-induced brain impairment in young people: a review. Cortex $2013 ; 49(1): 3-17$.

[6] Toumbourou JW, Stockwell T, Neighbors C, Marlatt GA, Sturge J, Rehm J. Interventions to reduce harm associated with adolescent substance use. Lancet 2007; 369(9570): 1391-401.

[7] Welch KA, Carson A, Lawrie SM. Brain structure in adolescents and young adults with alcohol problems: systematic review of imaging studies. Alcohol Alcohol 2013; 48(4): 433-44.

[8] Grant BF, Dawson DA. Age at onset of alcohol use and its association with DSM-IV alcohol abuse and dependence: results from the national longitudinal alcohol epidemiologic survey. J Subst Abuse 1997; 9: 103-10.

[9] Hibell B, Guttormsson U, Ahlström S, et al. The 2007 ESPAD report - substance use among students in 35 European countries. The Swedish council for information on alcohol and other drugs (CAN). Stockholm: Sweden. Available from: http://www.espad.org/espad-reports

[10] Komro KA, Stigler MH, Perry CL. Comprehensive approaches to prevent adolescent drinking and related problems. In: Galanter M, Eds. Recent developments in alcoholism, Alcohol problems in adolescents and young adults. Epidemiology, neurobiology, prevention, treatment. New York: Plenum Press 2005; vol. 17. pp. 207-24.

[11] Foxcroft DR, Tsertsvadze A. Universal school-based prevention programs for alcohol misuse in young people. Cochrane Database Syst Rev 2011; (5): CD009113.

[12] Foxcroft DR, Tsertsvadze A. Universal family-based prevention programs for alcohol misuse in young people. Cochrane Database Syst Rev 2011; (9): CD009308.

[13] Foxcroft DR, Tsertsvadze A. Universal multi-component prevention programs for alcohol misuse in young people. Cochrane Database Syst Rev 2011; (9): CD009307.

[14] Sancassiani F, Pintus E, Holte A, et al. Enhancing youths' emotional and social skills to promote their wellbeing and positive development: a systematic review of universal school-based randomized controlled trials. Clin Pract Epidemiol Ment Health 2015; 11: 21-40.

[15] Cossu G, Cantone E, Pintus M, et al. Integrating children with psychiatric problems in the classroom: a systematic review. Clin Pract Epidemiol Ment Health 2015; 11: 41-57.

[16] Champion KE, Newton NC, Barrett EL, Teesson M. A systematic review of school-based alcohol and other drug prevention programs facilitated by computers or the internet. Drug Alcohol Rev 2013; 32(2): 115-23.

[17] Caria MP, Faggiano F, Bellocco R, Galanti MR. EU-Dap Study Group. Effects of a school-based prevention program on European adolescents' patterns of alcohol use. J Adolesc Health 2011; 48(2): 182-8. 
[18] Clark HK, Ringwalt CL, Shamblen SR, Hanley SM. Project success' effects on substance use-related attitudes and behaviors: a randomized controlled trial in alternative high schools. J Drug Educ 2011; 41(1): 17-44.

[19] Conrod PJ, O'Leary-Barrett M, Newton N, et al. Effectiveness of a selective, personality-targeted prevention program for adolescent alcohol use and misuse: a cluster randomized controlled trial. JAMA Psychiatry 2013; 70(3): 334-42.

[20] D'Amico EJ, Tucker JS, Miles JN, Zhou AJ, Shih RA, Green HD Jr. Preventing alcohol use with a voluntary after-school program for middle school students: results from a cluster randomized controlled trial of CHOICE. Prev Sci 2012; 13(4): 415-25.

[21] Evers KE, Paiva AL, Johnson JL, et al. Results of a transtheoretical model-based alcohol, tobacco and other drug intervention in middle schools. Addict Behav 2012; 37(9): 1009-18.

[22] Gabrhelik R, Duncan A, Miovsky M, Furr-Holden CD, Stastna L, Jurystova L. "Unplugged": a school-based randomized control trial to prevent and reduce adolescent substance use in the Czech Republic. Drug Alcohol Depend 2012; 124(1-2): 79-87.

[23] Giannotta F, Vigna-Taglianti F, Galanti RM, Scatigna M, Faggiano F. Short-term mediating factors of a school-based intervention to prevent youth substance use in Europe. J Adolesc Health 2014; 54(5): 565-73.

[24] Kupersmidt JB, Scull TM, Austin EW. Media literacy education for elementary school substance use prevention: study of media detective. Pediatrics 2010; 126(3): 525-31.

[25] McCambridge J, Hunt C, Jenkins RJ, Strang J. Cluster randomised trial of the effectiveness of motivational interviewing for universal prevention. Drug Alcohol Depend 2011; 114(2-3): 177-84.

[26] Shek DT, Yu L. Prevention of adolescent problem behavior: Longitudinal impact of the project P.A.T.H.S. in Hong Kong. ScientificWorldJournal 2011; 11: 546-67.

[27] Sussman S, Sun P, Rohrbach LA, Spruijt-Metz D. One-year outcomes of a drug abuse prevention program for older teens and emerging adults: evaluating a motivational interviewing booster component. Health Psychol 2012; 31(4): 476-85.

[28] Werch CE, Bian H, Carlson JM, et al. Brief integrative multiple behavior intervention effects and mediators for adolescents. J Behav Med 2011; 34(1): 3-12.

[29] Vigna-Taglianti FD, Galanti MR, Burkhart G, Caria MP, Vadrucci S, Faggiano F. EU-Dap Study Group. "Unplugged," a European school-based program for substance use prevention among adolescents: overview of results from the EU-Dap trial. New Dir Youth Dev 2014; 2014(141): 67-82, 11-2.

[30] Anderson P, Chisholm D, Fuhr DC. Effectiveness and costeffectiveness of policies and programmes to reduce the harm caused by alcohol. Lancet 2009; 373(9682): 2234-46.

[31] Black DR, Tobler NS, Sciacca JP. Peer helping/involvement: An efficacious way to meet the challenge of reducing alcohol, tobacco, and other drug use among youth? J Sch Health 1998; 68(3): 87-93.

[32] Bruvold WH. A meta-analysis of the California school-based risk reduction program. J Drug Educ 1990; 20(2): 139-52.

[33] Carey KB, Scott-Sheldon LA, Elliott JC, Garey L, Carey MP. Face-to-face versus computer-delivered alcohol interventions for college drinkers: A meta-analytic review, 1998 to 2010. Clin Psychol Rev 2012; 32(8): 690-703.

[34] Dejong W, Larimer ME, Wood MD, Hartman R. NIAAA's rapid response to college drinking problems initiative: reinforcing the use of evidence-based approaches in college alcohol prevention. J Stud Alcohol Drugs Suppl 2009; (16): 5-11.

[35] Gottfredson DC, Wilson DB. Characteristics of effective schoolbased substance abuse prevention. Prev Sci 2003; 4(1): 27-38.

[36] Pan W, Bai H. A multivariate approach to a meta-analytic review of the effectiveness of the D.A.R.E. program. Int J Environ Res Public Health 2009; 6(1): 267-77.

[37] Porath-Waller AJ, Beasley E, Beirness DJ. A meta-analytic review of school-based prevention for cannabis use. Health Educ Behav 2010; 37(5): 709-23.

[38] Thomas RE, McLellan J, Perera R. School-based programmes for preventing smoking. Cochrane Database Syst Rev 2013; 4: CD001293.

[39] Thomas R, Perera R. School-based programmes for preventing smoking. Cochrane Database Syst Rev 2006; (3): CD001293.

[40] Turrisi R, Ray AE. Sustained parenting and college drinking in first-year students. Dev Psychobiol 2010; 52(3): 286-904.
[41] Andrews JA, Gordon JS, Hampson SE, et al. Short-term efficacy of Click City ${ }^{\circledR}$ : Tobacco: changing etiological mechanisms related to the onset of tobacco use. Prev Sci 2011; 12(1): 89-102.

[42] Blaakman S, Tremblay PJ, Halterman JS, Fagnano M, Borrelli B. Implementation of a community-based secondhand smoke reduction intervention for caregivers of urban children with asthma: process evaluation, successes and challenges. Health Educ Res 2013; 28(1): 141-52.

[43] Blalock SJ, Casteel C, Roth MT, Ferreri S, Demby KB, Shankar V. Impact of enhanced pharmacologic care on the prevention of falls: a randomized controlled trial. Am J Geriatr Pharmacother 2010; 8(5): 428-40.

[44] Blank MB, Hanrahan NP, Fishbein M, et al. A randomized trial of a nursing intervention for HIV disease management among persons with serious mental illness. Psychiatr Serv 2011; 62 (11): 1318-24.

[45] Bosi S, Gorini G, Tamelli M, et al. A school-based peer-led smoking prevention intervention with extracurricular activities: the LILT-LdP cluster randomized controlled trial design and study population. Tumori 2013; 99(5): 572-7.

[46] Butz AM, Halterman JS, Bellin M, et al. Factors associated with completion of a behavioral intervention for caregivers of urban children with asthma. J Asthma 2012; 49(9): 977-88.

[47] Caria MP, Faggiano F, Bellocco R, Galanti MR. The influence of socioeconomic environment on the effectiveness of alcohol prevention among European students: a cluster randomized controlled trial. BMC Public Health 2011; 11: 312.

[48] Clark HK, Ringwalt CL, Shamblen SR, Hanley SM, Flewelling RL. Are substance use prevention programs more effective in schools making adequate yearly progress? A study of Project ALERT. J Drug Educ 2011; 41(3): 271-88.

[49] Clark HK, Ringwalt CL, Shamblen SR. Predicting adolescent substance use: the effects of depressed mood and positive expectancies. Addict Behav 2011; 36(5): 488-93.

[50] Conboy LA, Noggle JJ, Frey JL, Kudesia RS, Khalsa SB. Qualitative evaluation of a high school yoga program: feasibility and perceived benefits. Explore (NY) 2013; 9(3): 171-80.

[51] Cunningham RM, Whiteside LK, Chermack ST, et al. Dating violence: Outcomes following a brief motivational interviewing intervention among at-risk adolescents in an urban emergency department. Acad Emerg Med 2013; 20(6): 562-9.

[52] Dalum P, Paludan-Müller G, Engholm G, Kok G. A cluster randomised controlled trial of an adolescent smoking cessation intervention: short and long-term effects. Scand J Public Health 2012; 40(2): 167-76.

[53] Donovan E, Wood M, Frayjo K, Black RA, Surette DA. A randomized, controlled trial to test the efficacy of an online, parent-based intervention for reducing the risks associated with college-student alcohol use. Addict Behav 2012; 37(1): 25-35.

[54] Drieling RL, Gardner CD, Ma J, Ahn DK, Stafford RS. No beneficial effects of pine bark extract on cardiovascular disease risk factors. Arch Intern Med 2010; 170(17): 1541-7.

[55] Evans WD, Wallace JL, Snider J. Pilot evaluation of the text4baby mobile health program. BMC Public Health 2012; 12: 1031.

[56] Falavigna A, Teles AR, Velho MC, et al. Impact of an injury prevention program on teenagers' knowledge and attitudes: results of the pense bem-caxias do sul project. J Neurosurg Pediatr 2012; 9(5): 562-8.

[57] Gao Y, Zhou H, Zhao H, et al. Clinical research of traditional Chinese medical intervention on impaired glucose tolerance. Am J Chin Med 2013; 41(1): 21-32.

[58] Gerald LB, Gerald JK, Zhang B, McClure LA, Bailey WC, Harrington KF. Can a school-based hand hygiene program reduce asthma exacerbations among elementary school children? J Allergy Clin Immunol 2012; 130(6): 1317-24.

[59] Gmel G, Venzin V, Marmet K, Danko G, Labhart F. A quasirandomized group trial of a brief alcohol intervention on risky single occasion drinking among secondary school students. Int J Public Health 2012; 57(6): 935-44.

[60] Go VF, Srikrishnan AK, Parker CB, et al. High prevalence of forced sex among non-brothel based, wine shop centered sex workers in Chennai, India. AIDS Behav 2011; 15(1): 163-71.

[61] Guilamo-Ramos V, Jaccard J, Dittus P, Gonzalez B, Bouris A, Banspach $\mathrm{S}$. The linking lives health education program: a randomized clinical trial of a parent-based tobacco use prevention program for african american and latino youths. Am J Public Health 2010; 100(9): 1641-7. 
[62] Guo R, He Q, Shi J, Gong J, Wang H, Wang Z. Short-term impact of cognition-motivation-emotional intelligence-resistance skills program on drug use prevention for school students in Wuhan, China. J Huazhong Univ Sci Technolog Med Sci 2010; 30(6): 7205.

[63] Guyll M, Spoth R, Crowley DM. Economic analysis of methamphetamine prevention effects and employer costs. J Stud Alcohol Drugs 2011; 72(4): 577-85.

[64] Halterman JS, Szilagyi PG, Fisher SG, et al. Randomized controlled trial to improve care for urban children with asthma: results of the school-based asthma therapy trial. Arch Pediatr Adolesc Med 2011; 165(3): 262-8.

[65] Haug S, Schaub MP, Venzin V, Meyer C, John U. Moderators of outcome in a text messaging (SMS)--based smoking cessation intervention for young people. Psychiatr Prax 2013; 40(6): 339-46.

[66] Hawkins JD, Oesterle S, Brown EC, Abbott RD, Catalano RF. Youth problem behaviors 8 years after implementing the communities that care prevention system: a community-randomized trial. JAMA Pediatr 2014; 168(2): 122-9.

[67] Hodder RK, Freund M, Bowman J, et al. A cluster randomised trial of a school-based resilience intervention to decrease tobacco, alcohol and illicit drug use in secondary school students: study protocol. BMC Public Health 2012; 12: 1009.

[68] Huang CM, Chien LY, Cheng CF, Guo JL. Integrating life skills into a theory-based drug-use prevention program: effectiveness among junior high students in Taiwan. J Sch Health 2012; 82(7): 328-35.

[69] Hutchinson SG, Mesters I, van Breukelen G, et al. A motivational interviewing intervention to PREvent PAssive Smoke Exposure (PREPASE) in children with a high risk of asthma: design of a randomised controlled trial. BMC Public Health 2013; 13: 177.

[70] Kypri K, Vater T, Bowe SJ, et al. Web-based alcohol screening and brief intervention for university students: a randomized trial. JAMA 2014; 311(12): 1218-24.

[71] Lammers J, Goossens F, Lokman S, et al. Evaluating a selective prevention programme for binge drinking among young adolescents: study protocol of a randomized controlled trial. BMC Public Health 2011; 11: 126.

[72] Luna-Adame M, Carrasco-Giménez TJ, Rueda-García Mdel M. Evaluation of the effectiveness of a smoking prevention program based on the 'life skills training' approach. Health Educ Res 2013; 28(4): 673-82.

[73] Malmberg M, Overbeek G, Kleinjan M, et al. Effectiveness of the universal prevention program 'Healthy School and Drugs': study protocol of a randomized clustered trial. BMC Public Health 2010; 10: 541 .

[74] Mares SH, van der Vorst H, Lichtwarck-Aschoff A, et al. Effectiveness of the home-based alcohol prevention program "In control: No alcohol!": study protocol of a randomized controlled trial. BMC Public Health 2011; 11: 622.

[75] McCambridge J, Day M, Thomas BA, Strang J. Fidelity to motivational interviewing and subsequent cannabis cessation among adolescents. Addict Behav 2011; 36(7): 749-54.

[76] McFarlane E, Burrell L, Crowne S, et al. Maternal relationship security as a moderator of home visiting impacts on maternal psychosocial functioning. Prev Sci 2013; 14(1): 25-39.

[77] Midford R, Cahill H, Foxcroft D, et al. Drug education in Victorian schools (DEVS): the study protocol for a harm reduction focused school drug education trial. BMC Public Health 2012; 12: 112.

[78] Miovsky M, Novak P, Stastna L, Gabrhelik R, Jurystova L, Vopravil J. The effect of the school-based unplugged preventive intervention on tobacco use in the Czech Republic. Adicciones 2012; 24(3): 211-7.

[79] Moore MJ, Werch CE, Bian H. Pilot of a computer-based brief multiple-health behavior intervention for college students. J Am Coll Health 2012; 60(1): 74-80.
[80] Newton NC, Teesson M, Barrett EL, Slade T, Conrod PJ. The CAP study, evaluation of integrated universal and selective prevention strategies for youth alcohol misuse: study protocol of a cluster randomized controlled trial. BMC Psychiatry 2012; 12: 118.

[81] Okuyemi KS, Zheng H, Guo H, Ahluwalia JS. Predictors of adherence to nicotine gum and counseling among African-American light smokers. J Gen Intern Med 2010; 25(9): 969-76.

[82] O'Leary-Barrett M, Mackie CJ, Castellanos-Ryan N, Al-Khudhairy N, Conrod PJ. Personality-targeted interventions delay uptake of drinking and decrease risk of alcohol-related problems when delivered by teachers. J Am Acad Child Adolesc Psychiatry 2010; 49(9): 954-63.e1.

[83] O'Neil A, Hawkes AL, Chan B, et al. A randomised, feasibility trial of a tele-health intervention for acute coronary syndrome patients with depression ('MoodCare'): study protocol. BMC Cardiovasc Disord 2011; 11: 8.

[84] Peng B, Ni J, Anderson CS, et al. Implementation of a structured guideline-based program for the secondary prevention of ischemic stroke in China. Stroke 2014; 45(2): 515-9.

[85] Philip PM, Parambil NA, Bhaskarapillai B, Balasubramanian S Evaluation of a specially designed tobacco control program to reduce tobacco use among school children in Kerala. Asian Pac J Cancer Prev 2013; 14(6): 3455-9.

[86] Ryb GE, Dischinger PC, Diclemente C, Auman KM, Kufera JA, Soderstrom CA. Impulsive or depressive personality traits do not impede behavioral change after brief alcohol interventions. J Addict Dis 2011; 30(1): 54-62.

[87] Schuckit MA, Kalmijn JA, Smith TL, Saunders G, Fromme K. Structuring a college alcohol prevention program on the low level of response to alcohol model: a pilot study. Alcohol Clin Exp Res 2012;36(7): 1244-52.

[88] Schulz DN, Candel MJ, Kremers SP, Reinwand DA, Jander A, de Vries H. Effects of a web-based tailored intervention to reduce alcohol consumption in adults: randomized controlled trial. J Med Internet Res 2013; 15(9): e206.

[89] Shetgiri R, Kataoka S, Lin H, Flores G. A randomized, controlled trial of a school-based intervention to reduce violence and substance use in predominantly Latino high school students. J Natl Med Assoc 2011; 103(9-10): 932-40.

[90] Sorensen G, Pednekar MS, Sinha DN, et al. Effects of a tobacco control intervention for teachers in India: results of the Bihar school teachers study. Am J Public Health 2013; 103(11): 2035-40.

[91] Stigler MH, Perry CL, Smolenski D, Arora M, Reddy KS. A mediation analysis of a tobacco prevention program for adolescents in India: how did project MYTRI work? Health Educ Behav 2011; 38(3): $231-40$

[92] Stotts AL, Northrup TF, Schmitz JM, et al. Baby's Breath II protocol development and design: a secondhand smoke exposure prevention program targeting infants discharged from a neonatal intensive care unit. Contemp Clin Trials 2013; 35(1): 97-105.

[93] Walker DD, Stephens R, Roffman R, et al. Randomized controlled trial of motivational enhancement therapy with nontreatmentseeking adolescent cannabis users: a further test of the teen marijuana check-up. Psychol Addict Behav 2011; 25(3): 474-84.

[94] Winters KC, Fahnhorst T, Botzet A, Lee S, Lalone B. Brief intervention for drug-abusing adolescents in a school setting: outcomes and mediating factors. J Subst Abuse Treat 2012; 42(3): 279-88.

[95] Wolfe DA, Crooks CV, Chiodo D, Hughes R, Ellis W. Observations of adolescent peer resistance skills following a classroombased healthy relationship program: a post-intervention comparison. Prev Sci 2012; 13(2): 196-205.

[96] Yeung WK, Tam WS, Wong TW. Clustered randomized controlled trial of a hand hygiene intervention involving pocket-sized containers of alcohol-based hand rub for the control of infections in longterm care facilities. Infect Control Hosp Epidemiol 2011; 32(1): 6776.

(C) Agabio et al.; Licensee Bentham Open.

This is an open access article licensed under the terms of the Creative Commons Attribution Non-Commercial License (http://creativecommons.org/licenses/by-nc/3.0/) which permits unrestricted, non-commercial use, distribution and reproduction in any medium, provided the work is properly cited. 